\title{
UNA APROXIMACIÓN CRÍTICA A LA DENOMINACIÓN DE ACCIONES DE COLABORACIÓN COMO NEUTRALES
}

\author{
A CRITICAL APPROACH TO THE DENOMINATION OF \\ COLLABORATION ACTIONS AS NEUTRAL
}

\begin{abstract}
Miguel Schurmann Opazo*
RESUMEN: El presente artículo pretende realizar un análisis crítico de la denominación de acciones de colaboración como neutrales y cómo ello ha afectado a su adecuado tratamiento a título de complicidad en la doctrina y jurisprudencia alemana. Se trata de comportamientos que aparentan ser inofensivos pero que posibilitan la realización de un delito a través de su ejecución u omisión, planteando la pregunta por las condiciones (objetivas o subjetivas) que deben verificarse en un comportamiento de carácter colaborativo para que a un sujeto le sea atribuido a título de complicidad el injusto cometido por otro. Luego de la exposición del problema teórico que esta categoría pretende abarcar, se intentará a demostrar, en primer lugar, la incorrección de la denominación y, con ello, del punto de partida habitual para el tratamiento de este grupo de casos, esto es, analizar los supuestos bajo los cuales un comportamiento pierde su carácter neutral. En segundo lugar, se pretende demostrar que la identificación de este grupo de casos se corresponde con un problema dogmático real que debe ser abordado por el Derecho penal bajo el análisis de subsunción propio del esquema de la complicidad.
\end{abstract}

Palabras clave: complicidad, acciones neutrales, comportamientos profesionales, límites de la participación punible.

ABSTRACT: The present article aims to perform a critical analysis of the denomination of collaborative actions as neutral and how this has affected ist proper treatment as complicity in the German doctrine and jurisprudence. These are behaviors that appear to be harmless, but enable the realization of a crime through its execution or omission, raising the question about the conditions (objective or subjective) that must be verified in a collaborative behavior in order for a subject to be attributed as title of complicity the unjust committed by another. After exposing the theoretical problem that this category aims to cover, we will try to demonstrate, in first place, the incorrectness of the denomination and, with it, the habitual starting point for the treatment of this group of cases, this is to analyze the assumptions under which a behavior loses its neutral character. Secondly, it is intended to demonstrate that the identification of this group of cases corresponds to a real dogmatic problem that must be addressed by the criminal law under the subsumption analysis proper to the complicity scheme.

Key words: Complicity, neutral actions, professional behavior, limits of punishable participation.

\section{INTRODUCCIÓN}

La posibilidad de que las acciones cotidianas, es decir, tanto acciones profesionales como aquellas denominadas neutrales, puedan ser calificadas como cooperación punible es

* L.L.M. U. Bonn. Profesor de Derecho penal, Universidad de Chile, Dirección postal: Pío Nono 1, Providencia, Región Metropolitana. Dirección electrónica: miguelschurmann@gmail.com. 
una de las preguntas más interesantes que ha requerido especial atención en Alemania en los últimos treinta años, no solo en la doctrina sino también en la jurisprudencia. Dicha pregunta ha sido abordada mediante un determinado grupo de casos, en los cuales la punibilidad de dichos comportamientos a título de complicidad ha sido muy discutida. Se trata de comportamientos que aparentan ser inofensivos ${ }^{1}$ pero cuya ejecución u omisión posibilita la realización de un delito, planteando la pregunta por las condiciones (objetivas o subjetivas) que deben verificarse para que a un sujeto le sea atribuido a título de complicidad el injusto cometido por otro.

Aquel interés teórico ha sido trasladado a nuestra cultura por distintas vías. Primero, a través de una extensa exposición del problema junto a una toma de postura por parte del autor español Ricardo Robles Planas en su obra dedicada a la participación delictiva y la delimitación normativa de esferas de responsabilidad ${ }^{2}$, así como de las repercusiones que dicha exposición generó en la discusión de habla hispana ${ }^{3}$. En segundo lugar, a través del tratamiento más bien tangencial que ha recibido el problema en nuestro país ${ }^{4}$ El planteamiento del problema en Alemania ha partido del siguiente diagnóstico: no existe una restricción normativa suficiente en el propio $\$ 27$ Código Penal alemán (StGB) para excluir la punibilidad de conductas neutrales. Ante ello se plantean las siguientes preguntas: ¿debe otorgársele un tratamiento especial -penalmente privilegiado- a estos comportamientos para limitar su punibilidad? En caso afirmativo, ¿en cuál nivel de la teoría general del delito? En el nivel del tipo objetivo, en la imputación subjetiva, en una mezcla de ambos, o en el nivel de la antijuridicidad, son algunas de las propuestas.

Pese a que el curso de la discusión alemana ha mostrado un progresivo acuerdo en los resultados de las propuestas ${ }^{5}$, este trabajo comienza con una evaluación del tratamiento habitual del tema como insatisfactorio. Dicha insatisfacción tiene raíces más profundas, dado que ella no se debe solo a la falta de reconocimiento de un criterio general y adecuado para determinar bajo qué parámetros un comportamiento no sospechoso puede constituir una complicidad punible, perdiendo su carácter de neutral o cotidiano -bajo la nomenclatura dominante-, sino principalmente a cómo las propuestas actuales en este ámbito se encuentran construidas sobre diagnósticos y principios incorrectos, por lo que dicha insatisfacción continuará mientras esas premisas no sean abiertamente rechazadas y reemplazadas por los fundamentos teóricos adecuados.

Así, constituye un presupuesto de este trabajo el rechazo a una consideración fenomenológica para la constitución de la categoría en cuestión, que tome como piedra angu-

\footnotetext{
${ }^{1}$ Este tipo de comportamiento abarca también a aquél que se encuentra en conformidad con determinados parámetros.

2 Robles Planas (2003).

3 A título meramente ejemplar: Rueda Martín (2015) pp. 35-86; Guzmán (2010) pp. 275-326; Tisnado Solís (2018); Roca de AGAPITO (2008).

${ }^{4}$ El tratamiento del fenómeno ha sido realizado desde distintos puntos de vista. A propósito de los límites de la complicidad, ver: Viveros (2013) pp. 659-675. La relevancia para el ámbito del derecho penal económico es destacada por Van Weezel a propósito de los delitos tributarios. VAn Weezel (2007) pp. 77 y ss.

${ }^{5}$ La convergencia de posiciones en el resultado es reconocida por van Weezel, quien la califica como una misma situación (las mismas características del hecho evaluado), observada desde perspectivas distintas. VAN WeEZel (2007) pp. 83 y s.
} 
lar de su razonamiento la apariencia o conformidad del comportamiento con parámetros diversos a los propios del Derecho penal, en vez de determinar si, y cómo, ese comportamiento puede ser subsumido en el esquema prototípico ${ }^{6}$ previsto para el cómplice ${ }^{7}$. En contra del diagnóstico inicial previamente señalado, el supuesto de hecho previsto para la regulación de la complicidad no constituye una categoría carente de contenido que, entonces, deba ser completada por medio de categorías generales de la imputación objetiva o subsidiado mediante una restricción ad hoc del dolo del partícipe.

De esta forma, el objetivo de esta investigación: se restringe a demostrar, en primer lugar, la incorrección de la denominación y, con ello, del punto de partida habitual del problema y, en segundo lugar, que, pese al error que implica la denominación dominante, la identificación de este grupo de casos se corresponde con un problema dogmático real que debe ser abordado por el Derecho penal, pero bajo las categorías correctas.

\section{EL PLANTEAMIENTOY ALCANCE DE LA DISCUSIÓN DOGMÁTICA RELATIVA A LA COMPLICIDAD A TRAVÉS DE ACCIONES NEUTRALES Y SU PERTINENCIA PARA NUESTRA CULTURA JURÍDICA}

La ciencia jurídico-penal ha mostrado un gran interés por hacerse partícipe de esta problemática. Las contribuciones a la discusión han sido numerosas ${ }^{8}$ y se han desarrollado desde la década del ochenta, principalmente ${ }^{9}$. El tema se ha revisado bajo diversos formatos, desde breves comentarios de sentencias hasta extensos libros ${ }^{10}$, recomendaciones para la elaboración de exámenes universitarios ${ }^{11}$ e inclusive propuestas para la determinación -en el proceso penal- de la idoneidad reconocible de una acción de complicidad para propósitos delictivos en el ámbito profesional ${ }^{12}$. Por ello, forzosamente se debe estar de acuerdo

\footnotetext{
${ }^{6}$ La referencia al esquema prototípico o esquema de la complicidad se realiza para enfatizar que el supuesto de hecho previsto en el artículo 16 del Código Penal no tiene por finalidad ampliar la tipicidad de la regla de comportamiento de la parte especial. En este sentido, dando cuenta suficientemente del asunto involucrado, ver Contesse (2018) pp. 121 y ss.

7 Una alternativa que debe ser desechada, aunque por razones que exceden al objeto de este trabajo, es privilegiar un análisis propio de una teoría general de la imputación del resultado (generalmente conocida como teoría de la imputación objetiva). La versión dominante de la teoría de la imputación objetiva se encuentra expuesta en Roxin (2007) $\$ 11$ imputación al tipo objetivo, pp. 342 y ss. La impertinencia de la teoría de la imputación objetiva, en tanto categoría de la parte general destinada a seleccionar cursos causales relevantes, no implica necesariamente la impertinencia de dicha teoría como esquema de interpretación de la ley penal, bajo la idea de normativizar las categorías y conceptos penales.

8 Kindhäuser califica la situación como un verdadero ramo de respuestas. KINDHÄUSER (2007) p. 356.

9 Existe un consenso en relación a que el mérito del reconocimiento moderno del problema debe serle atribuido a Jakobs, el cual retomó la problemática en una contribución del año 1977 (denominada "Prohibición de regreso" ver nota 18) y propuso que el tratamiento de las acciones neutrales fuese hecho mediante una ponderación entre libertad general de acción, por una parte, y determinadas necesidades político-criminales, por la otra, desarrollando un sistema de reglas y excepciones de atribución de responsabilidad penal. SCHNEIDER (2004) p. 311.

10 Algunos ejemplos son Kudlich (2004) y Rackow (2007).

11 Rotsch (2004) pp. 14 y ss.

12 Schröder (2011) pp. 633 y ss.
} 
con Amelung, quien hace décadas caracterizó a la complicidad a través de acciones neutrales como un "tema de moda"13.

La discusión se extiende no solo al tratamiento que deben recibir las denominadas acciones neutrales dentro de la dogmática de la participación, sino también a su alcance. Bajo la misma denominación son identificados casos heterogéneos, en los cuales se apelan a diversos principios para su tratamiento y solución. El alcance jurídico y filosófico de la discusión es enorme. Algunas preguntas que habitualmente emergen -correcta o incorrectamente- en esta discusión son: ¿̇se encuentra permitido restringir la libertad de acción y de ejercicio profesional a través de la penalización de comportamientos cotidianos?, ¿qué función y efecto tienen en la imputación jurídico-penal la prohibición de regreso y el principio de confianza?, ¿pueden dichas acciones ser calificadas como la realización de un riesgo permitido o lícito?, ¿cuál es el fundamento penal de la complicidad y puede dicho injusto fundar suficientemente también la punibilidad de esta clase de acciones?, ¿qué rol juegan las reglas y expectativas del ámbito comercial para la imputación jurídico-penal? ${ }^{14}$. El único consenso alcanzado en este ámbito radica (paradójicamente) en que un consenso general -ya sea sobre un tratamiento unitario o diferenciado de este grupo de casos- no ha sido alcanzado todavía ${ }^{15}$. Una revisión de las últimas contribuciones arroja que ellas han traído más complejidad que claridad al estado de la discusión ${ }^{16}$.

Las distintas propuestas de tratamiento dependen de diversos principios y, naturalmente, las acciones neutrales pueden ser analizadas desde distintos puntos de vista. Por una parte, se encuentran quienes sostienen que este grupo de casos debería ser tratado analíticamente como uno propio de la parte general del Derecho penal, dado que la pregunta se relaciona con los límites del comportamiento punible ${ }^{17}$. Por otra parte, se encuentran quienes sostienen que este problema tiene una posición conocida y determinada en la teoría de la participación, donde debe ser resuelto ${ }^{18}$. Adicionalmente, este tema tiene una notable importancia práctica en el ámbito del Derecho penal económico, por lo que muchos autores han tratado el problema de las acciones neutrales en relación con determinados tipos penales propios de dicho ámbito ${ }^{19}$. Esta importancia práctica se ha mostrado también en numerosas decisiones del $\mathrm{BGH}^{20}$, el cual ha desarrollado un criterio para resolver ese grupo

\footnotetext{
13 Amelung (1999) p. 9. Este interés no ha cesado con los años como lo demuestra una revisión a los comentarios elaborados por la dogmática penal alemana. Por todos ver JoecKs (2017) Nm. 49 y ss.

14 Si bien el planteamiento de todas o parte de estas preguntas depende del punto de partida del autor que trate este problema, el principal libro en que todas ellas son reunidas y tratadas es KudLich (2004).

15 Отто (2001) p. 436.

16 Wiegand (1998) p. 198. Este diagnóstico se ha ratificado con el tiempo, por todos ver JoecKs (2017) Nm. 49 y ss.

17 El primero en este sentido es paradigmáticamente JAKOBS (1977) pp. 1 y ss.

18 Opinan en ese sentido especialmente KINDHÄUSER (2007) y WiEgAND (1998), como lo prueba el título de su artículo.

19 Frisch (2002) pp. 539 y ss. En el mismo sentido también KIndHäUsER (2007) p. 356. Un buen ejemplo sobre la utilidad de la discusión lo constituye el artículo de Silva Sánchez sobre la punibilidad de los notarios en el marco de delitos de carácter económico. Silva Sánchez (2008) pp. 237 y ss. Otro lo constituye el ejercicio de Momsen sobre el delito de uso de información privilegiada. Momsen (2010) pp. 561 y ss.

20 Tribunal Supremo Federal Alemán, las siglas corresponden a la denominación original.
} 
de $\operatorname{casos}^{21}$. La pertinencia para el caso chileno de la discusión teórica llevada adelante en Alemania se muestra desde ya por la similitud que exhiben las reglas que extienden ${ }^{22}$ para el cómplice la punibilidad de los tipos de la parte especial en ambos sistemas jurídicos. De acuerdo al $\$ 27.1$ StGB, se sanciona como cómplice a "quien haya prestado dolosamente ayuda a otro para la comisión de un hecho doloso antijurídico" ${ }^{23}$. Por su parte, nuestro Código Penal establece en su artículo 16 que "son cómplices los que, no hallándose comprendidos en el artículo anterior [que regula a quienes se consideran como autores], cooperan a la ejecución del hecho por actos anteriores o simultáneos”. De acuerdo a la fórmula defendida por la doctrina dominante en Alemania, la cooperación o prestación de ayuda del cómplice debe haber posibilitado, facilitado, intensificado o asegurado la realización del tipo ${ }^{24}$. Entre nosotros, Garrido prevé como requisito que el cómplice haya realizado "una actividad con anterioridad o en forma simultánea a la comisión del hecho, que objetivamente importe una colaboración del actuar del autor" 25 .

Por cierto, esto no impide que el legislador regule este tipo de conductas, ya no bajo la categoría de la complicidad, sino derechamente estableciendo tipos penales en la parte especial que tipifiquen conductas que constituyan -materialmente- una cooperación con otras que pueden ser calificadas, en el mismo sentido, como principales. Un ejemplo de ello se encuentra en el artículo 97 No 4 inciso final del Código Tributario, el cual sanciona la confección, venta y facilitación de documentos de relevancia tributaria con el objeto de cometer o posibilitar la comisión de delitos relacionados con la adulteración de la base imponible de otro. Pues bien, en ese caso, la confección de boletas o facturas -comportamiento que podría ser calificado habitualmente como neutral-, y que de acuerdo con las reglas de la parte general contaría como un acto de colaboración con el delito de otro referida al tipo penal principal, es tipificado como un delito autónomo apartándose de la regulación general de la complicidad, y respecto de la cual el actuante responde a título de autor.

21 El criterio vigente del BGH se construyó fundamentalmente entre los años 1998 y 2000, a través de las sentencias BGH NStZ RR 1999, 184 ("el caso del notario"); BGHStV 2000, 479 ("el caso del folleto comercial”); y BGHSt 46, 107 ("el caso de la evasión tributaria"). En dichas sentencias se ha construido un criterio a imagen y semejanza del desarrollado por Roxin, esto es, proponiendo un criterio mixto (objetivo-subjetivo), pero erigiendo como decisivo a este respecto el conocimiento que el aportante tiene de los fines delictivos del autor principal, estableciendo la punibilidad cuando ese conocimiento es certero y previendo excepcionalmente la punibilidad de la conducta cuando el nivel de conocimiento se califica como uno propio del dolo eventual. Este criterio ha sido fundamentalmente confirmado (pese al mayor desarrollo del elemento objetivo propio de la teoría, a saber, la relación del sentido delictivo y la idoneidad reconociblemente delictiva del acto como límite al principio de confianza) en las sentencias más recientes: BGH NJW-RR 2011, 551 Rn. 48; BGH NJW 2012, 3177; y BGH wistra 2014, 176.

22 El carácter extensivo de la punibilidad no alude a que sea una ampliación del carácter típico de la conducta, sino que al carácter constitutivo de dicha regla (en oposición a uno meramente declarativo) en relación con la punibilidad del partícipe. En donde las normas que regulan la complicidad punible no constituyen conductas típicas, sino que referidas al tipo, en los términos utilizados primigeniamente por Beling. Ver ConTESSE (2018) pp. 121 y ss. Sobre el concepto de reglas constitutivas ver SEARLE (1997) pp. 44 y ss. Ver igualmente sección III.4

23 Traducción del $\$ 27$ del StGB realizada por Claudio López Díaz, disponible en https://www.unifr.ch/ddp1/ derechopenal/obrasjuridicas/oj_20080609_13.pdf

24 KindhäUser (2007) p. 355.

25 Garrido Montt (2017) pp. 419. 


\section{EL PROBLEMA DE LA DENOMINACIÓN DE LA CATEGORÍA: LA COMPLICIDAD A TRAVÉS DE ACCIONES NEUTRALES COMO UN PROBLEMA DE DESCRIPCIÓN DE LA ACCIÓN}

Comúnmente la denominación de un problema en la ciencia penal se encuentra en relación con la correlativa categoría dogmática. Por ejemplo, se relacionan en la parte general la delimitación entre coautoría y complicidad o entre tentativa y delito imposible con sus respectivas categorías. Sin embargo, para la denominación de la complicidad a través de acciones neutrales tiene normalmente primacía una connotación fenomenológica. Las distintas posiciones dogmáticas plantean criterios, ya sea referidos generalmente al conocimiento o a la adecuación del actuante a un determinado rol, para determinar cuándo la acción pierde su carácter cotidiano o neutral, como si dicho carácter tuviese alguna prioridad como criterio para determinar la punibilidad de una conducta. La más célebre descripción de este problema fue desarrollada por Wohlleben, quien sostuvo que bajo las denominadas acciones neutrales se puede entender a "cada acción que el ejecutor habría realizado frente a cualquier otro estando en la posición del autor, porque él con dicha acción persiguió un fin propio (independiente del autor principal y su hecho) lícito y no desaprobado legalmente" 26 . En el dogmática nacional la descripción del problema ha sido formulada por van Weezel en los siguientes términos: "[e]l problema de las acciones neutrales se refiere precisamente a los casos en que una persona, en el contexto del desempeño de su trabajo, otorga una prestación 'externamente' indiferente (esto es: que considerada en sí misma constituye a lo sumo un riesgo permitido), pero que es utilizada por otro para cometer un delito" ${ }^{27}$. Si dicha descripción del problema es útil para analizar este tipo de comportamiento bajo las categorías penales, será precisamente el objeto de análisis de este apartado.

\section{LA COMPLiCIDAD A TRAVÉS DE ACCIONES NEUTRALES COMO GRUPO DE CASOS: APROXIMACIÓN FENOMENOLÓGICA ${ }^{28}$ \\ Este ámbito de discusión dogmática es usualmente descrito por medio de $\operatorname{casos}^{29}$. Una correcta y concentrada recopilación de los casos más importantes es entregada por}

26 Wohlleben (1996) pp. 101 y ss. El texto principal constituye una traducción libre del original que es transcrito a continuación: "jede Handlung verstehen, die der Ausführende einem jeden anderen in der Lage des Täters gegenüber vorgenommen hätte, weil er mit der Handlung [...] tat- und täterunabhängige eigene, rechtlich nicht missbilligte Zwecke verfolgt". Dicha descripción ha sido recogida de forma general por la dogmática alemana. Por ejemplo, Ambos (2000) p. 721.

${ }^{27}$ VAn WeEzel (2007) p. 79.

${ }^{28}$ Es necesario precisar que la determinación del objeto de análisis mediante la agrupación de casos constituye una aproximación metodológica diversa a aquella que, por ejemplo, propicia Roxin (2007) pp. 230 y s., al plantear la necesidad de abrir el sistema dogmático a "la naturaleza de las cosas" o a las circunstancias reales. Dicho sistema reconoce que los casos no entregan criterios de valoración jurídica que permita delimitar adecuadamente el objeto de análisis y su tratamiento, pero facilita la explicitación de los criterios y del tratamiento diverso que pueden presentar determinados subgrupos de ellos.

29 Roxin criticó el tratamiento previo no unitario de la categoría en Roxin (1993) nm. 16. El uso de casos es útil no solo para describir el problema, sino también para posibilitar la delimitación entre tipos de comportamientos lícitos e ilícitos, es por ello que comúnmente son usados casos para la argumentación. Una interesante elaboración de grupos de casos fue desarrollada por Wohlleben, cuando presentó distintos casos como objeto de 
Rengier: "Ejemplos: la venta de un pan o un cuchillo de bolsillo o una herramienta (desatornillador o martillo) que es comprada por alguien que la utiliza para matar, lesionar o hurtar; la venta de fósforos a quien realiza un incendio posterior; la venta de un bebestible en el cual será mezclado un veneno para matar a otro; la venta de prendas de vestir para camuflarse; el arriendo de un vehículo para una banda de atracadores o para alguien que quiere transportar dinero al extranjero para cometer evasión de impuestos; el traslado del autor desde el lugar del delito por un taxista; la transferencia de dineros de clientes al extranjero por parte de un funcionario de un banco para evadir impuestos" 30 .

Con acento en los conocimientos de quien realiza la prestación, Roxin presenta una constelación de casos similar y agrega uno interesante relativo al Derecho penal del medio ambiente: “¡es cómplice en un delito en contra del medio ambiente quien conscientemente entrega material a un fabricante que en su elaboración infringe permanentemente las prescripciones medioambientales?" 31.

En el mismo sentido fenomenológico (pero desde un punto de vista propio de la criminología), sostiene Schneider que la etiqueta acciones neutrales constituye el descubrimiento del autor de cuello blanco (en el mismo sentido utilizado por Sutherland en EE.UU.) para la dogmática penal alemana ${ }^{32}$. Lo característico de dichos delitos es que el autor se aprovecha del margen de maniobra de su profesión para promover el hecho punible (los denominados crímenes ocupacionales) ${ }^{33}$. Característicamente esta clase de comportamientos se presenta en la delincuencia económica ${ }^{34}$, dado que es propio de dicha categoría que los delitos sean cometidos dentro de límites legales difusos y en el marco de acciones habitualmente legales ${ }^{35}$. Especial consideración ha tenido nuestro tema cuando se ha afirmado que la forma usual de hacer negocios, que se encuentra dentro de los límites de lo jurídicamente permitido, podría ser utilizada para servir a fines criminales. El descubrimiento teórico de ese tipo de comportamientos $-\mathrm{y}$ de ese tipo de agente- permite augurar que la relevancia de estas constelaciones de casos aumentará en el futuro.

su investigación y, posteriormente en el mismo texto, probó las soluciones de los distintos autores sobre ellos. Ver Wohlleben (1996) pp. 7 y ss., 32 y ss.

30 Rengier (2016) p. 436. El texto principal constituye una traducción libre del original que es transcrito a continuación: "Beispiele: Verkauf eines Brot- oder Taschenmessers oder Werkzeugs (Schraubenzieher, Hammer), das der Käufer zu einer Tötung, Verletzung oder einem Diebstahl benutzt; Verkauf von Streichhölzern an einen späteren Brandstifter; Verkauf eines Getränks, in das Gift gemischt werden soll, um jemanden zu töten; Verkauf von Kleidungsstücken zum Tarnen; Vermietung eines Fahrzeug an eine Diebesbande oder einen Täter, der damit, um Steuern zu hinterziehen, Gelder ins Ausland transportierten will; Fahrt von Täter zum Tatort durch Taxifahrer; Verlagerung von Kundengeldern ins Ausland durch Bankmitarbeiter, um Steuern zu hinterziehen”.

31 Roxin (1993) nm. 16. El texto principal constituye una traducción libre del original que es transcrito a continuación: "Ist es Beihilfe zu Umweltstraftaten, wenn jemand Material an einen Fabrikanten liefert, von dem ihm bekannt ist, daß dieser bei der Verarbeitung ständig gegen Umweltschutzvorschriften verstößt?".

32 Schneider (2004) p. 312. En el mismo sentido Amelung (1999) p. 9.

33 Meier (2016) p. 315. Este aspecto ha sido destacado también por el influyente Green (2013) pp. 42 y s.

34 Una presentación general de la criminalidad económica desde el punto de vista de la criminología es entregada por Meier. Meier (2016) pp. 314 y ss.

35 MeIER (2016) p. 318. 
En el mismo sentido, pero desde un punto de vista sociológico, intervienen en la discusión Lesch ${ }^{36}$ y Jakobs $^{37}$ fundándose en el diagnóstico sobre la sociedad moderna de Luhmann, la que se caracteriza por el carácter anónimo de sus contactos. Bajo dicho diagnóstico de la sociedad, las acciones neutrales serían un fenómeno frecuente y, por ello, no debiesen constituir un problema especial para el Derecho penal. Desde tal punto de vista, el ciudadano satisface determinados roles en la sociedad, donde un comportamiento típicamente profesional se encuentra normalmente permitido cuando la actividad es legal. Por eso es precisamente la neutralidad, o la conformidad del comportamiento con un rol, un fundamento para la impunidad de la acción ejecutada ${ }^{38}$.

Como es posible apreciar, la categoría fue construida por medio de casos y su acento se encuentra en la contemplación externa (no necesariamente penal) del comportamiento. Es por ello que el primer acercamiento a ella fue especialmente fenomenológico ${ }^{39}$. Sin embargo, resulta evidente que tanto dicho acercamiento como la denominada neutralidad no entregan las herramientas para determinar cuándo un comportamiento aparentemente neutral excepcionalmente puede ser punible, dado que el carácter no habitual de un comportamiento no dice relación alguna con su eventual tipicidad o punibilidad. Dicha determinación solo puede ser realizada bajo un ejercicio de subsunción e imputación que permita calificar al comportamiento como un injusto de acuerdo a las categorías propias del Derecho penal.

\section{2. ¿POR QUÉ SON USADAS COMILlaS O SIGNOS DE INTERROGaCión CUANDO LA DOCTRINA SE REFIERE A LAS ACCIONES NEUTRALES?}

No resulta claro qué implicaciones para la descripción de las acciones tiene el adjetivo neutral aquí utilizado. Desde una consideración propia del Derecho penal, ese predicado pareciera indicar que la acción sería impune, debido a su conformidad normativa. Una acción neutral para el Derecho penal sería entonces -y en términos conscientemente circulares- una conducta no relevante en términos penales. Ese podría ser el primer acercamiento cuando muchos autores consideran esa denominación como contradictoria. Niedermaier, Lesch, Kudlich y Meyer-Arndt ${ }^{40}$ titulan sus contribuciones también con un signo de interrogación. Autores como Lesch, Kudlich, Amelung y, entre nosotros, van Weezel, ocupan la palabra clave neutral o profesional entre comillas. Schneider presenta la contradicción abiertamente con el título: "Acciones neutrales: ¿un oxímoron en el Derecho

\footnotetext{
${ }^{36}$ LESCH (2014) pp. 464 y ss.

37 JаковS (1977) pp. 19 y ss.

${ }^{38}$ En este sentido argumenta Robles cuando afirma que las acciones neutrales son vistas en sí mismas como legales. Sin embargo, ellas pueden ser utilizadas para cometer delitos por otras personas auto-responsables. Robles Planas (2003) pp. 34 y ss.

39 Wiegand nombra a ese punto de vista como naturalista. WiEgAnd (1998) p. 204. Sin embargo, dicha denominación podría ser confusa, dado que la teoría de roles es (auto)clasificada como normativa -en oposición a naturalista. Es por ello que aquí se privilegia la denominación de este acercamiento como fenomenológico, en tanto la normatividad a la que dicha postura hace referencia es la normatividad propia de los contactos sociales y no la específicamente penal, que es a la que aquí se da primacía.

40 Niedermaier (1995) pp. 507 y ss.; Lesch (2001) pp. 986 y ss.; Kudlich (2008) pp. 221 y ss.; y MeyerARNDT (1989) pp. 281 y ss.
} 
penal?" 41 . La contradicción radica en que un comportamiento penalmente relevante no puede ser designado simultáneamente como neutral, en el caso de que sea utilizado el mismo parámetro para evaluarlo. La dicotomía fundamental en el Derecho penal radica -desde una perspectiva normativa- entre comportamientos punibles y los que no lo son, lo que es determinado primordialmente mediante tipos penales. Es por ello que la neutralidad como sinónimo de atipicidad o impunidad ${ }^{42}$ es superflua y no entrega criterio de utilidad alguna para el Derecho penal, especialmente para determinar el merecimiento de pena de esa clase de acciones.

Para la doctrina dominante resulta suficientemente claro que ese criterio no permite una clara delimitación de la complicidad" ${ }^{43}$. En las palabras de Otto: "[e]l recurso al negocio cotidiano, el comportamiento habitual o profesional encubre a dichos estados de cosas, porque semejantes conexiones se vinculan a situaciones penalmente irrelevantes. Sin embargo, dicha aproximación tampoco entrega un punto de referencia para determinar cuándo una situación habitualmente de carácter irrelevante para el Derecho penal, alguna vez podría ser penalmente relevante" ${ }^{44}$ y agrega en relación a su propio criterio de carácter subjetivo: "tan correcto como es la afirmación de que comportamientos cotidianos o profesionales no serían punibles -como comportamientos socialmente adecuados-, es riesgosa la identificación de acciones cotidianamente realizadas con acciones en las cuales el actuante sabe que promueve, facilita o posibilita la comisión de un delito" ${ }^{45}$. Una aproximación común al problema sostiene que la correspondencia entre la acción y los parámetros usuales de una actividad profesional normal no altera el carácter punible de dicha acción a título de complicidad ${ }^{46}$. Bajo otros argumentos concuerda con ese resultado Roxin cuando afirma que: "no hay acciones cotidianas per se, sino que el carácter de una acción es determinado a través del fin al que ella sirve" ${ }^{37}$. Es decir, la discusión planteada en los términos habituales nos llevaría a, primero, evaluar el carácter neutral o cotidiano de la acción -con una mayor o menor apreciación del contexto o de las intenciones del actuante-, dado que tal característica del comportamiento tendría prioridad lógica en el análisis propio de la imputación

\footnotetext{
${ }^{41}$ Traducción libre del título original en alemán: "Neutrale Handlungen: Ein Oxymoron im Strafrecht?”. De acuerdo a la RAE, oxímoron significa: "1. m. Ret. Combinación, en una misma estructura sintáctica, de dos palabras o expresiones de significado opuesto que originan un nuevo sentido, como en un silencio atronador".

42 BeCKemper (2001) p. 163.

43 KindHÄUSER (2007) p. 356 y RoXin (1995) p. 513.

${ }_{44}$ Traducción libre del original en alemán "Der Rückgriff auf das ,alltägliche Geschäft', das ,übliche' oder ,berufstypische Verhalten' verdeckt diesen Sachverhalt, denn derartige Bezüge knüpfen gedanklich an strafrechtlich irrelevante Sachverhalte an, geben aber keinen Anhaltspunkt dafür, wann ein ,üblicherweise' strafrechtlich irrelevanter Sachverhalt einmal strafrechtlich relevant sein kann".

45 Отто (1998) p. 202. Traducción libre del original en alemán: "So richtig daher die Aussage ist, ,alltägliches', ,berufstypisches' Verhalten sei als sozialadäquates Verhalten nicht strafbar, so gefährlich ist die Identifizierung der alläglich erbrachten Handlungen mit Handlungen, von denen der Handelnde weiß, sie fördern, ermöglichen oder erleichtern eine Deliktsbegehung".

46 Wiegand (1998) p. 201.

47 Roxin (1995) p. 515. Traducción libre del original en alemán: "es gibt keine Alltagshandlungen per se, sondern der Charakter einer Handlung wird durch den Zweck bestimmt, dem sie dient".
} 
jurídico-penal, y luego, solo en la medida en que descartamos dicho carácter, es posible continuar con el análisis propio de la teoría del delito.

\section{LAS ACCIONES NEUTRALES COMO Un PROBLEMA DE DESCRIPCIÓN DE LA ACCIÓN}

Sin embargo, la neutralidad aquí señalada puede tener otro significado. El punto de vista denominado previamente como fenomenológico no utiliza el adjetivo neutral desde una perspectiva penal, sino desde una meramente externa. En ese sentido, son utilizadas de forma completamente intercambiables las ideas de comportamientos neutrales o comerciales, adecuados social o profesionalmente, pese a que esas denominaciones pueden responder a distintos parámetros ${ }^{48}$. De esta forma, se realiza una acción que es calificada -por ejemplo- como profesional, si aquella acción es realizada de acuerdo a las reglas y/o expectativas que rigen dicha profesión. Esta evaluación dependerá de si el profesional realiza su trabajo habitual, sin características extraordinarias ${ }^{49}$.

¿Puede ser una acción neutral o profesional y al mismo tiempo punible? Ello depende del concepto jurídico-penal de acción que se sostenga. Cuando se opta por un concepto de acción clásico ${ }^{50}$ que no se define en referencia al tipo penal, sino que mediante la afirmación del carácter voluntario del movimiento corporal destinado a excluir del análisis penal básicamente situaciones de incapacidad física de evitación (por ejemplo, vis absoluta), como lo hace la construcción dogmática post finalista ${ }^{51}$, la descripción de la acción puede cargar solo con dificultades de forma simultánea a una calificación externa al Derecho penal. Esta postura se corresponde con una ordenación de la teoría general del delito que posicione a la acción como primera categoría de análisis o elemento base. Cuando se defiende una noción de acción en dichos términos y de causa en el sentido de conditio sine qua non, en donde son causas todas las condiciones necesarias que inciden en el resultado delictivo, la cualificación de la acción implica o carga con la valoración penal que permite distinguir a la causa relevante (por ejemplo, como realización de un riesgo no permitido). Por ello constituye una contradicción la afirmación simultánea del carácter neutral y punible de una misma acción. No tiene sentido plantear que la acción es neutral o adecuada profesionalmente y, al mismo tiempo, que la acción constituye la creación de un riesgo no permitido. Ello explica que el tratamiento habitual del tema haya girado en torno a la realización de una correcta y única calificación de la conducta: neutral o punible a título de complicidad, debido

\footnotetext{
48 Pese a que la evaluación de acciones profesionales y cotidianas es usualmente equivalente, Otto presenta una distinción entre ambos tipos, dado que solo los comportamientos profesionales implicarían el ejercicio de un derecho fundamental. Отто (1998) p. 441. Bajo dicha comprensión, la intercambiabilidad de las denominaciones no es plena. La misma línea argumentativa es seguida por Kudlich. KudLICH (2004) pp. 25 y ss.

49 Anscombe (2000) pp. 43 y ss. Sin embargo, ella aclara rápidamente que ese no es un juicio jurídico y que en caso alguno permite exculpar al agente de una imputación penal, por ejemplo, de homicidio. "It is not an ethical or legal interest; if what he said was true, that will not absolve him from gilt of murder!”, ANSCOMBE (2000) p. 45.

50 Kindhäuser denomina esa comprensión de la acción como "elemento base" bajo la comprensión dominante de la teoría del delito. KINDHÄUSER (2011) p. 57. Hruschka, por su parte, caracteriza dicho acercamiento como teoría de la acción naturalística o causal. HruschKa (1976) pp. 8 y ss.

51 La versión paradigmática en este sentido la constituye la teoría de la acción de Roxin, que la concibe como manifestación de la personalidad y la erige como el elemento básico de la teoría del delito. Roxin (1997) pp. 255 y ss.
} 
al sentido delictivo de la acción, en la medida en que se configuren los diversos parámetros normativos propuestos por la doctrina, tendientes a determinar cuándo una acción neutral pierde su carácter de tal y se torna en una complicidad punible, lo que, de acuerdo a la teoría de Roxin, es dependiente de la afirmación de que la conducta de colaboración imputada constituya el incremento causal de un riesgo no permitido ${ }^{52}$.

El uso del lenguaje en este sentido es absolutamente dominante en la doctrina y jurisprudencia alemanas. Así, en la paradigmática sentencia dictada en el caso de evasión tributaria ${ }^{53}$, el BGH sostuvo que el conocimiento del cooperador sobre la aptitud de su acto para ser valorado como una actuación en complicidad constituye un criterio para que su actuación pierda el carácter de cotidiano. Consecuencialmente, la sentencia afirma que dicho acto debe contar como una demostración de solidaridad con el autor y, por eso, no puede ser visto más como un acto adecuado socialmente, haciendo con ello referencia cumulativamente a diversos criterios planteados por la doctrina para determinar la punibilidad de una contribución de este tipo a título de complicidad. Por su parte, en la doctrina suele hacerse referencia dicotómicamente al sentido delictivo del acto en oposición a contribuciones de carácter neutral ${ }^{54}$, de forma que solo una vez que la acción es privada de su carácter de neutral o cotidiano puede serle atribuido la calificación de un acto de cooperación punible.

Sin embargo, cuando se acepta que un comportamiento se deja describir de distintas maneras ${ }^{55}$ y esa descripción es acuñada a través del interés cognitivo de quien la describe, la posibilidad de acceder simultáneamente a las mismas acciones, desde otros puntos de vista distintos al Derecho penal, como lo son el fenomenológico, naturalístico o sociológico, resulta evidente. Así, si la acción es entendida como la marca de agencia que le atribuye al agente un determinado evento como intencional, bajo un criterio intensional, es decir, relativo a una determinada descripción, la descripción de un mismo evento bajo distintas aproximaciones resulta obvio, y la calificación de la acción como neutral no dice, en principio, nada en relación con su punibilidad. Dicha constatación es compatible tanto con la comprensión de la acción como un constructo interpretativo en los términos propuestos por Kindhäuser ${ }^{56}$, o en un sentido extensional al estar referida a un evento singular, pero

\footnotetext{
52 Roxin (2014) pp. 291 y ss.

53 BGHSt 46, 107.

54 Así por ejemplo, Tisnado Solís (2018) p. 185, y Viveros (2013) p. 672 quien afirma, respecto de una conducta auxiliar que se adapta al fin del autor principal, "que esa conducta no es inocente ni neutra sino que, al revés, concreta una participación criminal plenamente consciente y dolosa, pues de lo contrario resultaría bien inexplicable su adaptación al hecho delictivo posterior”. En el mismo sentido van Weezel al hacer referencia a la solución en el marco del lado subjetivo del hecho. VAN WEEZEL (2007) p. 81.

55 De acuerdo con la relatividad de la descripción, Moore (2009) pp. 263 y ss.; Anscombe (2000) p. 11, "since a single action can have many different descriptions"; y SEARLE (1997) p. 183, "toda representación es real bajo un determinado punto de vista y no bajo otro"; KINDHÄUSER (1989) pp. 52 y ss.

56 Fundamental KINDHÄUSER (2011) pp. 41 y ss. Un punto de vista similar puede ser asumido cuando es usada la teoría de la acción de Hruschka, dado que ella postula como acción la imputación de un movimiento corporal según la aplicación de una regla. Así, un comportamiento puede ser evaluado como profesional de acuerdo a un determinado parámetro de dicha profesión, y dicho parámetro puede estar referido a un sistema articulado de reglas o no (como expectativa). HRUSChKa (1976) pp. 12 y ss., p. 33.
} 
susceptible -a su vez- de múltiples descripciones verdaderas, en los términos planteados por Davidson, y seguido entre nosotros por Mañalich ${ }^{57}$. Si bien no existe un límite cierto para evitar un amplio espectro de posibles descripciones de una acción, ello no significa que todas ellas sean en la misma medida relevantes para quien las evalúa ${ }^{58}$.

Una acción individualizada desde una perspectiva ex post entrega una explicación del comportamiento ajeno ${ }^{59}$ y eso puede ser visto como el resultado de un proceso de imputación de intenciones ${ }^{60}$. Un buen ejemplo en dicho sentido lo entrega Kindhäuser: "una persona se mueve -por ejemplo- corriendo por la calle. Ese comportamiento puede ser interpretado de diversas formas como una acción (intencional): P huye de la policía; P quiere alcanzar su tren; P trota; P omite tocar su violín; y muchas más" ${ }^{61}$. Ese enjuiciamiento a través de un tercero puede descomponerse en dos elementos: la observación del comportamiento físico (movimiento corporal) ${ }^{62}$ y una interpretación adscriptiva de la intención que lo gobierna. Así, la intención no puede ser deducida solamente a partir del comportamiento físico, sino que es necesaria también la facultad para comprender el sentido de los comportamientos $^{63}$. Sin embargo, dicha interpretación realizada por un tercero es necesariamente hipotética, dado que el actuante puede postular otra interpretación de su acción con la finalidad de debilitar la interpretación atribuida ${ }^{64}$. Por ejemplo, "yo solo hice mi trabajo", cuando el actuante vende un cuchillo a otro que tiene como objetivo matar a un tercer ${ }^{65}$. Con otras palabras, de acuerdo con una determinada descripción del comportamiento (no) tuvo el actuante la intención de hacer algo (o de evitarlo).

Un comportamiento puede ser descrito correctamente tanto en primera persona como también desde la perspectiva de uno o más observadores ${ }^{66}$. Es por ello precisamente que una acción puede ser descrita sin problemas desde una perspectiva interpretativa como

\footnotetext{
57 En los términos propuestos por Davidson "a man is he agent of an act if what he does can be described under an aspect that makes it intentional”. Sin embargo, una acción intencional bajo otra descripción puede ser al mismo tiempo inintencionada. Lo importante, para los efectos de adscribir agencia es que la acción (en un sentido extensional) sea intencional bajo alguna de sus posibles descripciones. DAvidSON (2001) pp. 43 y ss. Mañalich (2014) pp. 59 y ss., 71. Para estos efectos no es necesario tomar partido entre una tesis extensionalista o intensionalista para la individualización de eventos en los términos expuestos por Mañalich. Agradezco el comentario formulado por el profesor Javier Contesse para explicitar de mejor forma este punto.

58 MACKIE (1980) pp. 32 y s.

59 Brennenstuhl (1980) pp. 53 y ss.

60 Von Wright (1971) pp. 88 y ss.; Hruschka (1976) pp. 18 y ss.

${ }^{61}$ Kindhäuser (2015) p. 255. Traducción libre del original en alemán: "Eine Person bewegt sich z.B. auf der Straße rennend fort. Dieses Verhalten kann in unterschiedlicher Weise als [intentionelle] Handlung interpretiert werde: P flieht vor der Polizei; P will ihren Zug erreichen; P joggt; P unterlässt es Geige zu spielen - und vieles mehr".

62 Previamente bajo la denominación de fundamento in re. HruschKa (1976) pp. 12 y s., 33. Así también KINDHÄUSER (1982) pp. 493 y s.

63 Anscombe (2000) p. 53.

${ }^{64}$ KINDHÄUSER (2011) p. 42 y s. En el ejemplo nombrado arriba podría el corredor afirmar y probar que él debía llegar urgentemente a un baño.

65 O “yo no pude evitarlo", cuando un jarrón fue arrojado debido a un viento muy fuerte. KINDHÄUSER (1982) p. 494.

${ }^{66}$ Brennenstuhl (1980) p. 59; KindhäUser (2011) pp. 47 y ss. De acuerdo con la compatibilidad de distintos puntos de vista, también VON Wright (1971) p. 129.
} 
neutral o profesional y, al mismo tiempo, como punible. Es importante notar que, para la imputación penal, el interés cognitivo relativo a la comprensión del comportamiento se encuentra impregnado por las reglas de comportamiento, las que fijan el comportamiento esperado, permitiendo imputar al agente una determinada intención en relación al seguimiento de la norma, y que al momento de realizar de forma ex post el juicio de atribución de responsabilidad penal, la primacía en la imputación de la intención le corresponde al juez $^{67}$. Así, el juez interpreta el comportamiento objetivo del autor de acuerdo a la intención que puede serle atribuida en relación al seguimiento de la norma de comportamiento que le resultaba vinculante en esa situación, en tanto ella cuenta como una oportunidad para la acción ${ }^{68}$ y no en relación a cuál fue realmente la intención que el actuante se autoatribuye o postula al momento de desarrollar su comportamiento, la cual carece de importancia para estos efectos. Debido a ello, cada comportamiento aparentemente neutral puede tener relevancia penal, pero solo bajo otra descripción. Lo que en cualquier caso resulta inaceptable desde la perspectiva de la teoría de las normas es afirmar que una acción penalmente relevante debe ser permitida debido a su falta de dañosidad bajo alguna otra descripción posible ${ }^{69}$.

La acción es construida o individualizada interpretativamente por el Derecho penal. Así, el objeto de la imputación es determinado desde una perspectiva ex post mediante un juicio de subsunción del comportamiento, destinado a evaluar la satisfacción del supuesto de hecho previsto condicionalmente en la norma de sanción de la parte especial del Derecho penal. A partir de dicha norma de sanción puede ser deducida una norma de comportamiento que, en tanto prohibición o mandato, establece la obligación para el destinatario de ajustar su comportamiento a ella, de modo de no realizar la acción prohibida o de modo de realizar la acción ordenada ${ }^{70}$. Bajo esta perspectiva, cuando el destinatario tuvo (o debió haber tenido) el conocimiento y la capacidad para evitar el injusto típico, y no lo hizo, es posible designar dicho comportamiento como un injusto de acción. En otras palabras, el reproche penal supone - desde una perspectiva ex post- que una persona ha realizado el supuesto de hecho del tipo penal, pero solo cuando él tuvo la oportunidad -desde una perspectiva ex ante- de haberlo evitado intencionalmente.

Dado que la norma de comportamiento debe ser reconocida de forma vinculante como una razón para la acción, el reproche asociado al injusto de su quebrantamiento proviene de su falta de reconocimiento como tal ${ }^{71}$. Con ello, la imputación penal implica una

\footnotetext{
67 Vogel (1993) pp. 68 y ss.

68 Fundamental para determinar el concepto de la oportunidad para la acción y su relevancia para la descripción de la acción, ver Von Wright (1963) capítulo III, nm. 3. Ver también Von Wright (1971) pp. 125 y ss.; BRenNenstuhl (1975) pp. 199 y s.; KindHÄUser (1989) pp. 50 y ss.; y MañAlich (2014) pp. 73 y s.

69 KindhäUSER (2018) p. 52.

70 El esquema de análisis para desarrollar deberes de acción concretos para el autor ha sido latamente desarrollado de la mano del silogismo práctico. Fundamental para ello Von Wright (1971) pp. 96 y ss.; AnsCOMBE (2000) pp. 57 y ss.; Brennenstuhl (1980) pp. 52 y ss.; KindHÄUser (1989) pp. 54 y ss.; KindHÄUser (2011) pp. 47 y ss.; Vogel (1993) p. 71. Críticamente MACKIE (1980) pp. 289 y ss. La utilidad de este esquema para establecer deberes de abstenerse de realizar acciones auxiliares lo ha probado Brennenstuhl. BRENNENSTUHL (1975) pp. 217 y ss.; y BRENNENSTUHL (1980) pp. 60 y ss.

71 Mañalich (2014) p. 20.
} 
interpretación del hecho punible cuyo contenido de injusto es la infracción imputable de la norma de comportamiento ${ }^{72}$. Los ejemplos a partir de los cuales el argumento anterior demuestra ser operativo son numerosos. Wiegand entrega, para estos efectos, dos: "bajo determinados requisitos, estar dormido pacíficamente en su propia cama puede fundar responsabilidad penal -como por ejemplo, para el garante que debe cumplir con su función de vigilancia para proteger un bien jurídico en peligro. Y también una autoría en comisión puede radicar en acciones aparentemente neutrales, por ejemplo, cuando el autor vierte un terrón de azúcar en el café de otro y ese, debido a que es diabético, resulta lesionado por ello"73. Esos ejemplos muestran que casi toda acción externamente no dañosa -de acuerdo con una determinada descripción- puede ser merecedora de pena -bajo otra descripción-, y que su apariencia externa no puede entregar un criterio decisivo en materia penal para distinguir entre comportamientos punibles y no punibles ${ }^{74}$.

Una correcta descripción de la acción puede ser alcanzada desde el punto de vista de la teoría dominante, cuando se recurre a una descripción de la acción dependientedel-contexto ${ }^{75}$. El problema de dicha noción es que asume que existe solo una descripción correcta en términos absolutos, la que debe ser formulada atendiendo al contexto en que la acción es ejecutada, mientras que la postura aquí defendida es que existe una descripción pertinente para el Derecho penal, cuyos criterios de pertinencia son fijados por las reglas de comportamiento, complementadas -entre otras- por el esquema prototípico correspondiente al cómplice. Especial aprobación merece el juicio de Kindhäuser al respecto: "la cotidianidad de una acción no es con ello una característica que -en sí misma- pueda oponerse a la constitución del injusto" ${ }^{\text {. }}$.

De esta forma, el Derecho penal identifica el objeto de la imputación de acuerdo con su propio interés cognitivo, el que esta determinado prioritariamente por las reglas de comportamiento de la parte especial y, en lo que a actos de colaboración se refiere, por el esquema prototípico del cómplice, el cual vincula a los tipos de la parte especial con un comportamiento que sea calificable objetivamente como una colaboración, bajo una relación de accesoriedad a un injusto principal en los términos previstos por la dogmática de la partici-

72 KindHÄUSER (1989), pp. 43 y ss. Así también Hruschka, quien define la imputación como un juicio en el que alguien es tenido como autor de una acción bajo una regla. HrusCHKA (1976) pp. 30 y ss.

73 Wiegand (1998), p. 205. Traducción libre del original en alemán: "Unter bestimmten Voraussetzungen kann selbst das friedliche Schlafen im eigenen Bett Strafbarkeit begründen - etwa für den Garanten, der gerade seinen Wachdienst zum Schutz gefährdeten Rechtsgutsobjekte erfüllen müsste. Und auch Begehungstäterschaft kann in äußerlich neutral erscheinenden Handlungen liegen, etwa dann, wenn der Täter eine kräftige Prise Zucker in den Kaffee eines anderen schüttet und diesen, da er Diabetiker ist, dadurch körperlich schädigt”.

74 Acertado en este sentido Mañalich (2014) p. 89.

75 Kudlich (2004) pp. 172 y ss. En este sentido, esta posición considera como complicidad punible la realización de una actuación normal en el ámbito profesional cuando el contexto del acto expresa una alta densidad delictiva. Esta discrepancia es identificada entre nosotros por van Weezel (VAN WeEZEL (2007) p. 83) y se corresponde básicamente con la discrepancia entre la que correspondería a la postura del primer Jakobs a favor de la impunidad de dicha conducta, defendida en la actualidad por Lesch, y la postura actualmente defendida por Jakobs, en donde la considera como un acto de complicidad punible. JAKOBS (2014) p. 28.

76 KIndHÄUSER (2007) p. 371. Traducción libre del original en alemán: "Die Alltäglichkeit einer Handlung ist daher, für sich gesehen, keine Eigenschaft, die der Konstitution von Unrecht entgegenstehen könnte”. En el mismo sentido, pero refiriéndose a los comportamientos socialmente adecuados en KINDHÄUSER (2010) p. 408. 
pación delictiva. De modo que la delimitación del objeto de análisis penalmente relevante a título de complicidad no depende del carácter neutral o habitual de una conducta, sino que de su posible calificación como una acción auxiliar o de colaboración con una principal que satisface un supuesto de hecho previsto por un tipo penal de la parte especial y respecto de la cual no concurre una causal de justificación, en los términos generalmente aceptados de accesoriedad limitada.

Así, resulta bastante claro que la acción neutral no constituye una categoría dogmática, sino que es el resultado de una (limitada) perspectiva fenomenológica que se basa en un comportamiento que sigue determinadas pautas y que, adicionalmente, tiene normalmente la apariencia de un acto irrelevante para el Derecho penal. Es por ello que Rackow propuso correctamente cambiar la denominación de la categoría por la de acciones no sospechosas. Pese a que dicha denominación tampoco entrega un criterio para delimitar la punibilidad de ese tipo de casos, ella es preferible debido al carácter abiertamente fenomenológico que expresa, el cual, por una parte, no intenta confundirse con categorías dogmáticas sustantivas $y$, por la otra, destaca un aspecto que puede ser de relevancia para fines propios del proceso penal ${ }^{77}$.

No obstante lo anterior, estas reflexiones no impiden integrar en el juicio de imputación penal una o más características fenomenológicas comunes de las denominadas acciones neutrales, en la medida en que ello sea el resultado interpretativo de las normas que regulan la materia y, en especial para el problema que nos atañe, en la medida en que ellas sean de utilidad en la búsqueda de una solución correcta para determinar cuándo este tipo de acciones podría contar como complicidad punible.

\section{4. ¿LAS ACCIONES PROFESIONALES COMO UN ÁMBITO REGULATIVO ESPECIAL?}

Una parte de la literatura ${ }^{78}$ defiende otra postura en relación a la utilidad del adjetivo neutral en la descripción de acciones con relevancia penal, especialmente para comportamientos que sean calificables como profesionales. Así, se ha afirmado que, pese a que no habrían acciones propiamente neutrales (en tanto no son en sí mismas, y desde todas las perspectivas, neutrales), dicha calificación podría ser útil en relación a determinados contextos (profesionales) para delimitar comportamientos merecedores de pena de aquellos que deben permanecer no criminalizados. Kudlich entrega dos argumentos para ello: (i) por una parte, existen protocolos de comportamientos (lex artis) vinculantes en ámbitos profesionales, los cuales permiten enjuiciar un comportamiento como normal o, al contrario, como ajustado delictivamente en relación a la acción principal posterior; (ii) por la otra, es reconocible en las acciones profesionales una determinación abstracta y general hacia la realización de la actividad, sin relación a determinada persona.

Debido a la multiplicidad e independencia de los contactos - por su carácter anónimo-, el profesional tendría, por una parte, un riesgo alto de que su acción sea llevada a un

\footnotetext{
77 Rackow (2007) pp. 44 y ss. De acuerdo Отто (2008) p. 422. En este ámbito propone Schröder un método procesal para probar la idoneidad reconocible de la contribución para un delito posterior. SCHRÖDER (2011) pp. 638 y ss.

78 Principalmente Kudlich (2004) pp. 172 y ss. y Hassemer (1995) pp. 42 y ss., 81 y ss.
} 
contexto criminal y, por la otra, ese comportamiento estereotipado entregaría un parámetro para evaluar cuándo una acción profesional perdió su normalidad ${ }^{79}$. El criterio más importante, en este sentido, sería el concepto de adaptación de la acción en relación con el resultado posterior $^{80}$. Si bien el hecho de que la motivación del autor no pueda entregar una razón ${ }^{81}$ para distinguir entre comportamientos punibles y no punibles (sino solo la ausencia o la carencia de un reconocimiento efectivo de la norma de comportamiento penal como razón para la acción) no puede ser tratado con mayor profundidad aqui ${ }^{82}$, la incorrección de ese argumento general no debe llevarnos a perder de vista la razón más relevante para realizar una consideración especial en la valoración de comportamientos de carácter profesional: la existencia de reglas y expectativas en dicho ámbito ${ }^{83}$.

A diferencia de las acciones cotidianas, que no conocen parámetro alguno distinto a la habitualidad o mera repetición, las acciones profesionales son evaluables bajo normas de distinta clase. En este sentido, las acciones profesionales pueden albergar una relación normativa ${ }^{84}$. El cumplimiento de reglas y expectativas profesionales puede tener influencia sobre la valoración de la acción, desde un punto de vista penal. Precisamente por ello Hassemer propuso una investigación sobre la especial normatividad presente en determinados ámbitos profesionales, para así evaluar la influencia de dichas normas y expectativas en la imputación jurídico-penal. No obstante, para desarrollar dicho proyecto de investigación, primero debe indagarse en qué tipos de reglas y expectativas existen en dicho ámbito y, posteriormente, qué efecto puede tener un comportamiento que se ajuste a ellas. Pese a que en el Derecho penal pueden ser reconocidas paradigmáticamente normas de comportamiento y reglas de imputación ${ }^{85}$, los ámbitos profesionales pueden ser construidos por un espectro más amplio de normas. Si bien existen distintas clasificaciones de normas, el interés cognitivo radica aquí, precisamente, en el efecto que dichas normas y expectativas tendrían sobre la valoración penal del comportamiento ${ }^{86}$. La conocida distinción de Searle ${ }^{87}$

\footnotetext{
79 Dicha reflexión es compartida por la teoría de Jakobs y es usada para la descripción del contenido de un rol social. Ver sección III.1.

${ }^{80}$ Kudlich (2004) p. 182. Quien nombra dos criterios adicionales para afirmar la neutralidad de una acción. Cuando (i) la acción no ha ocasionado inmediatamente el resultado; y (ii) cuando a través de la acción el actuante directo no ha sido apoyado objetiva y externamente.

81 Dicha motivación puede tener correlativamente un punto de vista normativo, cuando la motivación se funda en el derecho fundamental del artículo 12 de la Constitución alemana (GG por sus siglas en alemán, correspondientes a la traducción literal de Ley Fundamental). Sin embargo, el argumento a oponer a la antijuridicidad de la conducta ya no sería el ánimo o la motivación del autor, sino que el ejercicio de un derecho fundamental o la realización de una conducta que debe ser calificada como lícita al amparo del referido derecho fundamental.

82 Ver sección III.3 con ulteriores referencias ahí indicadas.

83 Hassemer (1995) pp. 82 y ss.

${ }^{84}$ Von Wright denomina dicha relación como "relación bajo la norma”. Von Wright (1963) Capítulo VII, nm. 8 .

85 Sobre esta distinción ver fundamentalmente HrUSCHKA (2009) pp. 11 y ss.

86 Algunas características decisivas para describir normas son su origen, jerarquía, contenido y función. Ver VON Wright (1963) Capítulo 5, donde se encuentra un análisis fundamental desde el punto de vista de la teoría de las normas.

87 SeArle (1997) pp. 44 y ss.; así también Von Wright (1971) pp. 151 y ss.
} 
entre reglas regulativas y reglas constitutivas permite desarrollar una primera aproximación al problema. Pese a que ambas clases de reglas tienen una función regulativa, tanto su forma de regular como su vinculación con el comportamiento son distintas. Mientras las reglas constitutivas regulan un comportamiento que no puede ser descrito con independencia de dichas reglas, las reglas regulativas son aquellas respecto de las cuales la descripción del comportamiento regulado puede ser hecho con independencia de dichas reglas. Un típico ejemplo de reglas constitutivas en este sentido son las reglas de juegos o del lenguaje ${ }^{88}$, los que se corresponden con la idea de hechos institucionales en la construcción teórica de Searle ${ }^{89}$. Sin embargo, es fácilmente imaginable también la previsión de dicho tipo de reglas en ámbitos profesionales. Por ejemplo, existen reglas para determinar cuándo una venta de valores puede ser reconocida como tal dentro del mercado de capitales. Dichas reglas tienen aquí una función constitutiva y, por ello, no pueden influir en la valoración penal de la acción. En nuestro ejemplo, pese a que el cumplimiento de esas reglas tiene el efecto de permitir que la acción sea reconocida como una venta de valores, dicho cumplimiento no tiene la aptitud para cambiar la valoración penal de la acción. En otras palabras, el cumplimiento de dichas reglas no permite la calificación de la venta como legal, sino solo la calificación de la acción como venta dentro del sistema del mercado de valores. Es precisamente por ello que queda abierta la posibilidad de valorar la venta como ilegal en base a otros parámetros normativos. Por ejemplo, por el uso de información privilegiada en ella o por haber sido realizada para manipular el mercado, entre otras posibles razones ${ }^{90}$.

Por otra parte, se encuentran las reglas regulativas, las cuales se caracterizan por ostentar un carácter prescriptivo. Dichas reglas pueden ser dispuestas junto a reglas constitutivas, de modo de permitir la explicación del comportamiento para el caso en que la acción regulada se refiera a hechos institucionales. Sin embargo, ello no es siempre necesario ${ }^{91}$. Las reglas regulativas pueden tener también un distinto origen, jerarquía, contenido y función. Por ejemplo, el Código Penal contiene -entre otras- reglas de sanción, las que permiten a su vez inferir pragmáticamente reglas de comportamiento. Los ámbitos profesionales pueden reconocer prescripciones, tanto internas como externas, con un carácter regulativo. Es importante destacar que la valoración sobre la suficiencia de un sistema normativo interno para regular adecuadamente una actividad no puede ser hecha como un todo, como Hassemer parece proponer, sino solo individualmente, regla por regla, en un determinado con-

\footnotetext{
88 "Rules", bajo la denominación de von Wright. Junto a ese tipo de reglas se encuentran "directivas y normas técnicas" (directives or technical norms), las que proponen instrucciones. VON WRIGHT (1963) Capítulo I, nm. 4. y 7.

${ }^{89}$ Dado que dicha idea asume la existencia de instituciones humanas y sigue la estructura " $\mathrm{X}$ cuenta como $\mathrm{Y}$ en el contexto C". SeArLe (1997) pp. 21 y ss., especialmente el capítulo IV.

${ }^{90}$ Por esta vía se reafirma también -una vez más- la posibilidad de que una acción pueda ser objeto de distintas descripciones, ya sea desde perspectivas normativas (como aquí) o fenomenológicas, manteniéndose todas ellas como potencialmente correctas. Parte de la discusión del conocido "caso Cascadas" en nuestro país fue planteada en estos términos.

${ }^{91}$ La conocida objeción de Raz contra una distinción estricta entre reglas constitutivas y reglas regulativas, porque toda regla contiene una dimensión constitutiva, debe ser parcialmente aceptada en los términos señalados por González Lagier. GonZÁLEZ LaGier (1993).
} 
texto de aplicación ${ }^{92}$, de acuerdo a la lógica jurídico-penal y sus categorías propias. Dado que una acción lícita según las regulaciones profesionales sectoriales puede tener otra significación desde un punto de vista penal ${ }^{93}$, la prioridad analítica de las reglas penales $-\mathrm{y}$ su vinculatoriedad para el ciudadano por sobre lo dispuesto en los ordenamientos sectorialesno puede ser puesta en duda en la valoración de las conductas, dado que en caso contrario se presentaría el absurdo de que eventuales autorizaciones infralegales tendrían el efecto de preterir la vigencia de prohibiciones penales ${ }^{94}$. Es por ello que el cumplimiento de las normas y expectativas profesionales, que constituyen un determinado rol, no puede resultar decisivo para la valoración jurídico-penal de una conducta, sino solo el cumplimiento de las reglas de comportamiento penales, las que se encuentran referidas finalmente al rol de un ciudadano fiel al derecho.

Pese a que una evaluación de la acción dentro de ámbitos profesionales con pretensiones de exhaustividad sería errónea si no atendiese a las normas de comportamiento penales, ello no significa que las reglas y expectativas dentro de dichos ámbitos carezcan de relevancia para una valoración penal de la conducta. Tal como se señaló previamente, la valoración de dichas reglas debe ser realizada necesariamente una a una y por medio de la interpretación de los elementos de los tipos penales de la parte especial, en conexión con las reglas de atribución de autoría y participación de la parte general. Un buen ejemplo de ello lo constituye el reconocimiento de reglas de cuidado internas establecidas en los ámbitos profesionales, las que ayudan a la valoración de una acción como imprudente. Incluso las costumbres profesionales, que se corresponden con determinadas expectativas, pueden tener relevancia penal cuando la pregunta se trate sobre qué cuenta como cooperación en el sentido de la regla que sanciona la colaboración con el delito de otro a título de complicidad, dado que solo puede contar como colaboración en este sentido una contribución a la comisión del delito que no sea la meramente esperada en relación con cualquier contacto anónimo en la sociedad. Es precisamente por ello que aquí es preferida una consideración desacoplada de dichas regulaciones, atendiendo a su pertinencia en un contexto de aplicación determinado.

\section{A MODO DE CONCLUSIÓN, ¿CONSTITUYE ESTO UN PROBLEMA APARENTE PARA EL DERECHO PENAL?}

Independientemente del tratamiento de este grupo de casos, la discusión en torno a las (mal) denominadas acciones neutrales ha tenido el mérito de destacar el problema de la determinación de la mínima entidad que debe tener una contribución accesoria para ser merecedora de punibilidad. En otras palabras, aquí nos enfrentamos al problema del límite

\footnotetext{
92 GÜNTHER (1995).

93 Ver sección III.3.

94 No es casual que los tipos penales no realicen una referencia a la profesión del autor u otra característica irrelevante del hecho. Por otra parte, como correctamente ha sido argumentado en otro contexto, los ciudadanos no se encuentran capacitados para decidir por sí mismos cuándo y bajo qué condiciones se encuentran vinculados por las normas penales de un ordenamiento jurídico.
} 
inferior de la complicidad punible ${ }^{95}$. Mientras que con anterioridad la dogmática penal se ocupaba con frecuencia de la delimitación entre coautoría y complicidad, es decir, de intentar dar claridad a una delimitación de categorías dentro del marco de lo punible ${ }^{96}$, gracias a la emergencia de este problema en la discusión -o más bien de su identificación fenomenológico-, el interés por delimitar las acciones auxiliares merecedoras de pena de aquellas que no lo son ha tomado un nuevo impulso. Con ello, y a diferencia de una equivocada conclusión que podría haberse extraído de lo señalado precedentemente, el problema de la denominación afecta al análisis y tratamiento de las acciones de complicidad aparentemente inofensivas, en tanto objeto de imputación, pero en caso alguno implica que las (mal) denominadas acciones neutrales constituyan un problema dogmático meramente aparente o imaginario; al contrario, constituye un asunto jurídico de real interés científico, lo que se demuestra fácilmente por las numerosas contribuciones que se han escrito sobre este problema a nivel universal ${ }^{97}$, junto a los múltiples casos y criterios de delimitación que han sido propuestos por la dogmática penal para su tratamiento ${ }^{98}$. Esta preocupación procede frecuentemente del rechazo de la que Lesch identifica como usual fórmula de la antigua jurisprudencia alemana: resultado + causalidad + dolo $=$ responsabilidad $^{99}$. Es por ello que se plantean diversas restricciones normativas para excluir del ámbito de lo punible a las colaboraciones mínimas. Sin embargo, dicha discusión primeramente debe ser ordenada mediante una correcta identificación y calificación de su objeto y eso fue lo que se pretendió hacer aquí.

\section{BIBLIOGRAFÍA CITADA}

Амвоs, Kai (2000): "Beihilfe durch Alltagshandlungen”, Juristische Arbeitsblätter: pp. 721-725. Amelung, Knut (1999): “Die ,Neutralisierung' geschäftsmäßiger Beiträge zu fremden

Straftaten im Rahmen des Beihilfetatbestands", en SAMsOn, Erich et al. (editor), Festschrift für Grünwald (Baden-Baden, Nomos) pp. 9-30.

Anscombe, Elizabeth (2000): Intention (Cambridge, Harvard University Press).

Beckemper, Katharina (2001): "Strafbare Beihilfe durch alltägliche Geschäftsvorgänge", Jura, No 3: pp. 163-169.

95 De forma consciente Wiegand utiliza como título para su contribución en esta problemática el de "límites de la complicidad punible" ("Grenzen strafbarer Beihilfe") Wiegand (1998). En el mismo sentido también VIVEROs (2013), al elegir como título de su artículo "sobre los límites de la complicidad" y denominar el apartado especialmente referido a este problema como "Complicidad vs. Impunidad" (pp. 667 y ss.).

96 En donde la "teoría del dominio del hecho" juega un rol fundamental en la tradición continental. Una revisión sobre su influencia en la doctrina y jurisprudencia chilena se encuentra en VIVEROs (2013) pp. 660 y ss.

${ }^{97}$ Para informarse sobre el tratamiento del tema en la discusión anglosajona, para los crímenes del nacionalsocialismo y en el derecho penal internacional, ver RACKOW (2007) p. 437 y ss. En el ámbito anglosajón ver HuRD (2001) pp. 307-340; Duff (1990) p. 165, 181 y Moore (2009) p. 292. En España, ver Robles Planas (2003) pp. 24 y ss., con referencias ulteriores. Como puede fácilmente ser notado, en otros países son utilizados ejemplos muy parecidos para tratar este grupo de casos.

98 Para una revisión de los textos en nuestro ámbito cultural que exponen estos criterios ver las notas 3, 4, y 5 .

99 LESCH (2001) p. 987. La fórmula proviene de Lesch, pese a que el contenido de cada categoría es discutido. Entre nosotros una postura similar ha planteado van Weezel "desde el punto de vista dogmático, lo verdaderamente relevante es que la imputación no puede fundarse en la mera causación dolosa”. VAN WeEzel (2007) p. 85. 
Brennenstuhl, Waltraud (1980): “Ziele der Handlungslogik", en LenK, Hans (editor), Handlungstheorien interdisziplinär I (Múnich, Wilhem Fink Verlag) pp. 35-66.

Brennenstuhl, Waltraud (1975): Handlungstheorie und Handlungslogik (Kronberg, Scriptor-Verlag).

Contesse, Javier (2018): "Tentativa de delito y concurso de personas en el hecho punible en la obra de Eduardo Novoa Monreal”, en Ambos, Kai y GuzMán, José Luis (editores), Derecho y cambio social. Estudios criticos en homenaje a Eduardo Novoa Monreal (Santiago, DER Ediciones) pp. 113-140.

Davidson, Donald (2001): Essays on Actions and Events (Oxford, Clarendon Press).

Duff, Antony (1990): “Can I Help You?' Accessorial Liability and the Intention to Assist”, Legal Studies, No 10: pp. 165-181.

FrISCH, Wolfgang (2002): "Beihilfe durch neutrale Handlungen”, en PrITTwITZ, Cornelius et al. (editor), Festschrift für Klaus Lüderssen (Baden-Baden, Nomos) pp. 539-557.

Garrido Montt, Mario (2017): Derecho Penal Parte General, tomo II (Santiago, Editorial Jurídica de Chile).

González Lagier, Daniel (1993): "Clasificar acciones. Sobre la crítica de Raz a las reglas constitutivas de Searle”, Doxa, No 13: pp. 265-276. Disponible en: http://www.cervantesvirtual.com/descargaPdf/clasificar-acciones-sobre-la-crtica-de-raz-a-las-reglas-constitutivas-de-searle-0/. Fecha de consulta: 21 de mayo de 2019.

Green, Stuart (2013): Mentir, hacer trampas y apropiarse de lo ajeno (Madrid, Marcial Pons).

GÜNTHER, Klaus (1995): "Un concepto normativo de coherencia para una teoría de la argumentación jurídica”, Doxa-Cuadernos de Filosofía del Derecho, No 17-18: pp. 271302. Disponible en: http://www.cervantesvirtual.com/descargaPdf/un-concepto-normativo-de-coherencia-para-una-teora-de-la-argumentacin-jurdica-0/. Fecha de consulta: 21 de mayo de 2019.

GuZmán, Nicolás (2010): "Conductas neutrales y participación en el delito", en PASTOR, Daniel (director) y GuZMán, Nicolás (coordinador), Problemas actuales de la Parte General del Derecho Penal (Buenos Aires, Ed. Ad Hoc) pp. 275-326. Disponible en: SSRN: https://ssrn.com/abstract=2956331. Fecha de consulta: 21 de mayo de 2019.

Hassemer, Winfried (1995): "Professionelle Adäquanz. Bankentypisches Verhalten und Beihilfe zur Steuerhinterziehung”, parte I, Wistra, No 2: pp. 41-46.

Hassemer, Winfried (1995): "Professionelle Adäquanz. Bankentypisches Verhalten und Beihilfe zur Steuerhinterziehung”, parte II, Wistra, No 3: pp. 81-87.

HruschKa, Joachim (1976): Strukturen der Zurechnung (Berlín, Walter de Gruyter).

HrusCHKA, Joachim (2009): "Reglas de comportamiento y reglas de imputación”, en HrusCHKA, Joahim, Imputación y Derecho Penal (Montevideo y Buenos Aires, Editorial BdeF) pp. 11-29.

Hurd, Heidi (2001): "Is it wrong to do right when others do wrong?", Legal Theory, No 7: pp. 307-340.

JoECKS, Wolfgang (2017): Münchener Kommentar zum Strafgesetzbuch (MüKo-StGB), S 27 (Múnich, C.H.Beck) 
JAKOBS, Günther (1977): "Regreßverbot beim Erfolgsdelikt. Zugleich eine Untersuchung zum Grund der strafrechtlichen Haftung für Begehung”, Zeitschrift für die gesamte Strafrechtswissenschaft, No 89: pp. 1-35.

JaKOBS, Günther (2014): Theorie der Beteiligung (Tubinga, Mohr Siebeck).

KINDHÄUSER, Urs (1982): “Kausalanalyse und Handlungszuschreibung”, GA: pp. 477-498.

KIndHäUser, Urs (1989): Gefährdung als Straftat (Fráncfort del Meno, Vittorio Klostermann).

Kindhäuser, Urs (2007): "Zum Begriff der Beihilfe", en Dannecker, Gerhard et al. (editor), Festschrift für Harro Otto (Fráncfort del Meno, Heymanns) pp. 355-371.

KindHÄUser, Urs (2010): “Zum sog. „unerlaubten“ Risiko”, en Bloy, René et al. (editor), Gerechte Strafe und legitimes Strafrecht, Festschrift für Manfred Maiwald (Berlín, Duncker \& Humblot) pp. 397-416.

Kindhäuser, Urs (2011): “Zum strafrechtlichen Handlungsbegriff”, en PaeffGen, Hans-Ullrich et al. (editor), Festschrift für Ingeborg Puppe (Berlín, Duncker \& Humblot) pp. 39-54.

Kindhäuser, Urs (2015): "Zur Kausalität im Strafrecht”, en Albrecht, Peter-Alexis et al. (editor), Festschrift für Walter Kargl (Berlín, BWV- Berliner Wissenschafts-Verlag) pp. 253-272.

KindHÄUser, Urs (2018): "Welzels Konzeption sozialer Adäquanz - normtheoretisch betrachtet”, en Hecker, Bernd et al. (editores), Festschrift für Rudolf Rengier (Berlín, Verlag C.H. Beck) pp. 49-58.

KudLICH, Hans (2004): "Die Unterstützung fremder Straftaten durch berufsbedingtes Verhalten”, Strafrechtliche Abhandlungen. Neue Folge, tomo 156 (Berlín, Duncker \& Humblot).

Kuduich, Hans (2008): "Tiroler Gastfreundschaft auch für deutsches Geld - Anstiftung zur Steuerhinterziehung durch berufsbedingtes Verhalten?”, en SIEBER, Ulrich (editor), Festschrift für Klaus Tiedemann (Colonia, Heymann) pp. 221-236.

LESCH, Heiko (2001): “Strafbare Beteiligung durch „berufstypisches“ Verhalten?”, Juristische Arbeitsblätter: pp. 986-991.

LESCH, Heiko (2014): “Beihilfe durch „rollenadäquates“ Verhalten?”, en WAHLE, Eberhard et al. (editor), Festschrift für Wolf Schiller (Baden-Baden, Nomos), pp. 448-473.

MaCKIE, John (1980): The Cement of the Universe (Oxford, Clarendon Press).

Mañalich, Juan Pablo (2014): Norma, causalidad y acción (Madrid, Marcial Pons).

MeIer, Bernd (2016): Kriminologie (Múnich, C.H.Beck).

Meyer-Arndt, Lüder (1989): "Beihilfe durch neutrale Handlungen?", Wistra, No 8, pp. 281-287.

Momsen, Carsten (2010): "Neutralen Verhaltensweisen und Unterlassungen im Insiderstrafrecht”, en Bloy, René et al. (editor), Gerechte Strafe und legitimes Strafrecht, Festschrift für Manfred Maiwald (Berlín, Duncker \& Humblot) pp. 561-584.

Moore, Michael (2009): Causation and Responsibility (Nueva York, Oxford University Press).

Niedermaier, Harald (1995): "Straflose Beihilfe durch neutrale Handlungen?", Zeitschrift für die gesamte Strafrechtswissenschaft, No 107: pp. 507-544. 
Отто, Harro (2001): “Das Strafbarkeitsrisiko berufstypischen, geschäftsmäßigen Verhaltens", Juristische Zeitung, No 9: pp. 436-444.

Отто, Harro (1998): “„Vorgeleistete Strafvereitelung“ durch berufstypische oder alltägliche Verhaltensweisen als Beihilfe”, en Eser, Albin et al. (editor), Festschrift für Theodor Lenckner (Múnich, C.H. Beck) pp. 193-225.

Отто, Harro (2008): "Buchbesprechung Rackow, Peter: Neutrale Handlungen als Problem des Strafrechts", Zeitschrift für die gesamte Strafrechtswissenschaft, No 120: pp. 418-425.

Rackow, Peter (2007): Neutrale Handlungen als Problem des Strafrechts (Fráncfort del Meno, Peter Lang).

Rengier, Rudolf (2016): Strafrecht Allgemeiner Teil (Múnich, C.H. Beck).

Robles Planas, Ricardo (2003): La participación en el delito: fundamentos y límites (Madrid, Marcial Pons).

Roca de Agapito, Luis (2008): "Límites de la responsabilidad penal por actividad (profesional) cotidiana”, Estudios Penales y Criminológicos, vol. XXVIII Servizo de Publicacións da Universidade de Santiago de Compostela, ISSN 1137-7550, pp. 343-395. Disponible en:https://minerva.usc.es/xmlui/bitstream/handle/10347/4139/pg_343-396_ep28. pdf?sequence=1 \&isAllowed=y. Fecha de consulta: 21 de mayo de 2019.

Rотsсн, Thomas (2004): “'Neutrale Beihilfe' Zur Fallbearbeitung im Gutachten”, Jura, No 1: pp. 14-21.

Roxin, Claus (1993): Leipziger Kommentar (LK-StGB), IS 27 (Berlín y Nueva York, De Gryter).

Roxin, Claus (1995): “Was ist Beihilfe?”, en KüHne, Hans-Heiner (editor), Festschrift für Koichi Miyazawa (Baden-Baden, Nomos), pp. 501 -517.

Roxin, Claus (2007): Derecho Penal Parte General, tomo I (Madrid, Civitas).

Roxin, Claus (2014): Derecho Penal Parte General, tomo II (Madrid, Civitas).

Rueda Martín, María de los Ángeles (2015): "De nuevo sobre la relevancia penal de las acciones cotidianas en la comisión de un hecho doloso", Cuadernos de Política Criminal, No 115: pp. 35-86.

Schneider, Hendrik (2004): "Neutrale Handlungen: Ein Oxymoron im Strafrecht? -Zu den Grenzlinien der Beihilfe-", Neue Zeitschrift für Strafrecht: pp. 312-317.

SchröDER, Christian (2011): "Die berufstypische Beihilfe im Strafprozess: Methodisches zur Feststellung erkennbarer Tatgeneigtheit”, en GeIsLER, Claudius (editor), Festschrift für Klaus Geppert (Berlín y Nueva York,De Gruyter), pp. 633-642.

SEARLE, John (1997): La construcción de la realidad social (Barcelona, Paidos).

Silva Sánchez, Jesús María (2008): "Zur Beteiligung von Notaren an Vermögens und Wirtschaftsstraftaten”, en SIEBER, Ulrich (editor), Festschrift für Klaus Tiedemann (Colonia, Heymann) pp. 237-252.

Tisnado Solís, Luis (2018): Fundamentos normativos de la intervención delictiva y responsabilidad penal (Santiago de Chile, Editorial Hamurabi).

Van Weezel, Alex (2007): Delitos Tributarios (Santiago de Chile, Editorial Jurídica de Chile).

Viveros, Miguel (2013): "Sobre los límites de la complicidad", en VAn Weezel, Alex (coordinador), Humanizar y renovar el Derecho penal. Estudios en memoria de Enrique Cury (Santiago de Chile, Thomsom Reuters), pp. 659-675. 
Vogel, Joachim (1993): Norm und Pflicht bei den unechten Unterlassungsdelikten (Berlín, Duncker \& Humblot).

VON Wright, Georg (1963): Norm and Action (Londres, Routledge \& Kegan Paul).

VON Wright, Georg (1971): Explanation and Understanding (Londres, Routledge \& Kegan Paul).

WiEgand, Thomas (1998): "Grenzen strafbarer Beihilfe", en EsER, Albin (editor), Festschrift für Haruo Nishihara (Baden-Baden, Nomos), pp. 197-212.

Wohlleben, Marcus (1996): Beihilfe durch äußerlich neutrale Handlungen (Múnich, Verlag C.H. Beck. Münchener Universitätsschriften. Bd. 125). 
